\title{
ANALYSIS OF FLOW DATA FROM THE MG-T/DOE AMOCO FEE NO. 1 WELL \\ TOPICAL REPORT
}

S. K. GARG

$$
\text { NOTICE }
$$

PORTIONS OF THIS REPORT ARE ILLEGIBLE. It has been reproduced from the best available copy to permit the broadest possible availability.

\section{JANUARY 1982}

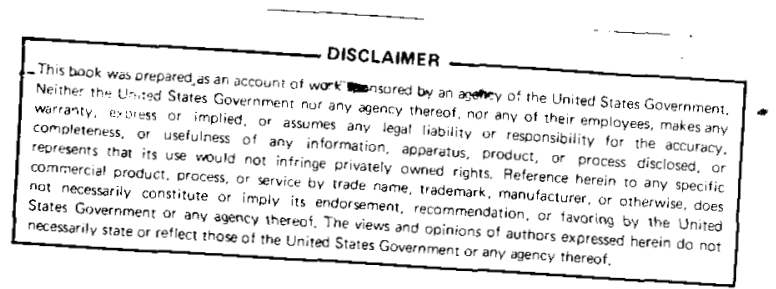

WORK PERFORMED UNDER CONTRACT

DE-AC08-80-NV10150

S-CUBED

P. O. BOX 1620

LA JOLLA, CA 92038

PREPARED FOR

DEPARTMENT OF ENERGY

NEVADA OPERATIONS OFFICE 


\section{DISCLAIMER}

This report was prepared as an account of work sponsored by an agency of the United States Government. Neither the United States Government nor any agency Thereof, nor any of their employees, makes any warranty, express or implied, or assumes any legal liability or responsibility for the accuracy, completeness, or usefulness of any information, apparatus, product, or process disclosed, or represents that its use would not infringe privately owned rights. Reference herein to any specific commercial product, process, or service by trade name, trademark, manufacturer, or otherwise does not necessarily constitute or imply its endorsement, recommendation, or favoring by the United States Government or any agency thereof. The views and opinions of authors expressed herein do not necessarily state or reflect those of the United States Government or any agency thereof. 


\section{DISCLAIMER}

Portions of this document may be illegible in electronic image products. Images are produced from the best available original document. 


\section{DISCLAIMER}

This report was prepared as an account of work sponsored by the United States Government. Neither the United States nor the United States Department of Energy, nor any of their employees, makes any warranty, express or implied, or assumes any legal liability or responsibility for the accuracy, completeness, or usefulness of any information, apparatus, product, or process disclosed, or represents that its use would not infringe privately owned rights. Reference herein to any specific commercial product, process, or services by trade name, mark, manufacturer, or otherwise, does not necessarily constitute or imply its endorsement, recommendation, or favoring by the United States Government or any agency thereof. The views and opinions of authors expressed herein do not necessarily state or reflect those of the United States Government or any agency thereof.

Available from:

National Technical Information Service

U. S. Department of Commerce

5285 Port Royal Road

Springfield, Virginia

22161

Price: Printed Copy $\$ 7.50$

Microfiche $\$ 4.00$ 
DOE/NV/10150-3

ANALYSIS OF FLOW DATA FROM THE MG-T/DOE AMOCO FEE NO. 1 WELL

TOPICAL REPORT

(SSS-R-82-5359)

S. K. Garg

January 1982

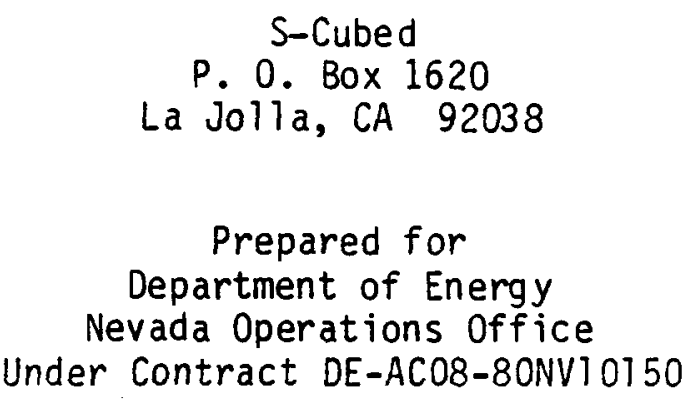




\section{ABSTRACT}

Analysis of buildup data from the Initial Flow Test indicates that the MG-T/DOE AMOCO Fee No. 1 Well penetrates a zone of relatively high permeability ( $162 \mathrm{md})$; this high permeability zone, however, extends to a radius of only about $200 \mathrm{ft}$ from the well. The far field permeability (i.e., for $r>200 \mathrm{ft}$ ) appears to be rather low $(\sim 11.9 \mathrm{md})$. (An alternate interpretation of the test data replaces the low permeability region beyond $200 \mathrm{ft}$ with two intersecting faults with a graben angle of $30^{\circ}$ located at about 200$250 \mathrm{ft}$ from the well.) The reservoir simulator MUSHRM together with the formation parameters inferred from the buildup data were successfully employed to history match the observed drawdown pressure data from both the Initial Flow Test and the Reservoir Determination Test. It appears that no reservoir boundaries were encountered during either of the flow tests. The inability of the well to sustain high production rates during the Reservoir Determination Test is believed to be due to the poor formation permeability encountered in the sand interval selected (fifth sand in the Miogyp sequence penetrated by the wel1). In any future testing of the well, it would be thus desirable to perforate additional sands in the Miogyp sequence. 


\section{TABLE OF CONTENTS}

Section

Page

I. INTRODUCTION AND BACKGROUND ............... 1

II. ANALYSIS OF BUILDUP DATA ...................... 9

2.1 Buildup Data Analysis ............ 10

2.2 Comparison with the Analysis of Gould, et al. .... 16

III. HISTORY-MATCH CLACULATIONS ............. 23

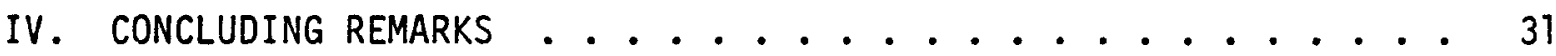

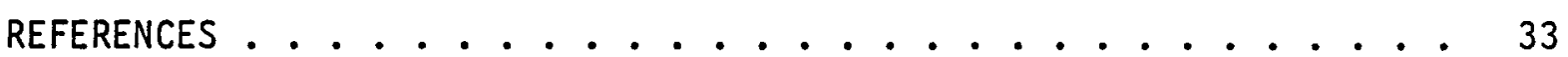

APPENDIX A: MG-T/DOE AMOCO Fee No. 1 Well: Test Data...... 35

APPENDIX B: PRESSURE ORAWDOWN SOLUTIONS .......... 39 
INTRODUCTION AND BACKGROUND

Since 1975, the U. S. Department of Energy (DOE) has funded an extensive deep drilling and well testing program to help evaluate the geopressured resources underlying the Gulf coast region of the United States. As part of this program, DOE executed a contract with Magma Gulf-Technadril (MG-T) to conduct the drilling, completion and testing of one geopressured well (i.e., MG-T/DOE AMOCO Fee No. 1 We11) in the Sweet Lake Geothermal-Geopressured Prospect (Cameron Parish, Louisiana). The subject well is located approximately 15 miles south of Lake Charles, Louisiana. A description of the geology of the prospect area, well completion, core data, and the test plan is given in a report by Durrett and Durham [1981].

The MG-T/DOE AMOCO Fee No. 1 Well penetrated eight potentially productive sands in the Miogyp sequence (depth interval 15,000 $15,640 \mathrm{ft}$ ). A single zone (i.e., fifth sand found between depths of 15,387 - 15,414 ft) of the eight sand sequence was selected for primary flow testing. Core analysis of the fifth sand indicated it had the nighest permeability of the eight sand sequence. Flow testing of the fifth sand was conducted in two distinct phases:

(A) Phase I - Initial Flow Test ( 3 days) and subsequent shutin to obtain buildup data ( 8 days).

(B) Phase II - Reservoir Determination Test ( 17 days).

The relevant flow rate/bottom hole pressure data for these tests were supplied to $S$-Cubed $\left(S^{3}\right)$ by Mr. Larry Durrett of Magma GulfTechnadril. The present report is concerned with the analysis of the pressure/flow data obtained during the two test phases. 
The MG-T/DOE AMOCO Fee No. 1 Well has a 5-1/2 inch production liner perforated over the interval 15,387 - 15,414 ft (mean depth $\sim 15,400.5 \mathrm{ft}$ ) in Miogyp sand. Bottom-hole pressure was measured using a Hewlett Packard quartz crystal gauge. Bottom-hole temperature $\left(\sim 299^{\circ} \mathrm{F}\right)$ was recorded prior to the start of the flow test. Independent surface pressure recording capability was also available. A Halliburton turbine pulse meter was used to record brine flow rates; the gas production rate was measured by flowing the gas through an orifice plate.

The pressure tool was set at a depth of $15,337 \mathrm{ft}$. The initial pressure at $15,337 \mathrm{ft}$ datum was measured at 12,053 psi. Assuming a static pressure gradient of $0.46 \mathrm{psi} / \mathrm{ft}$, the initial reservoir pressure (i.e., at 15,400.5 ft datum) becomes 12,082 psi. The brine produced from this well has a total dissolved solids content of $165,000 \mathrm{ppm}$ (i.e., 0.1487 by mass). With $p=12,082 \mathrm{psi}$, $T=299^{\circ} \mathrm{F}$, and $S=0.1487$, the $S^{3}$ methane/brine equation-of-state (Pritchett, et al. [1979]) yields a methane constent of 23.7 SCF/STB at saturation. Recombination measurements carried out by weatherly Laboratories, however, indicate ( $L$. Durrett, personai communication [1981]) that the gas/water ratio should be about 34 SCF/STB at saturation.

Brine flow rate measurements were made with the Halliburton turbine meter in fluid piped upstream of the separator to obtain immediate flow response from the wellhead, and to avoid the time lag downstream of the separator ( $L$. Durrett, personal communication [1981]). It should be noted that full stream flow (i.e., free gas and dissolved gas in addition to brine) is measured upstream of the separator, and not brine only. The presence of free gas in the flow stream appears to have caused the Halliburton turbine meter to 
behave erratically. Figures 1 and 2 show the pressure drawdown and the full stream flow data obtained during the two test phases. It is obvious from Figures 1 and 2 that something is wrong; the indicated changes in flow rate are not reflected in the pressure response. It, therefore, appears that the flow rate data are of doubtful validity. In his analysis of the Initial Flow Test, Garg [1981] assumed $q=3420 \mathrm{STB} / D$ for the first 2.74 days, and $q=2610$ STB/D for the remainder of the 3.07 day flow test. Gould, et al. [1981], on the other hand, assumed the following flow rates for the Initial Flow Test:

$$
\begin{aligned}
q & =3000 \text { BPD for } t \leq 0.92 \text { days } \\
& =3750 \text { BPD for } 0.92 \leq t \leq 2.8 \text { days } \\
& =2250 \text { BPD for } 2.8 \leq t \leq 3.07 \text { days }
\end{aligned}
$$

(The flow rate for the period $2.8 \leq t \leq 3.07$ days indicated in the Gould, et al. paper appears to be a misprint.) for the 17 day Reservoir Determination Test, Gould, et al. [1981] used the following flow schedule in their simulation:

$$
\begin{aligned}
q & =16,500 \text { BPD for } 0<t<0.1 \text { days } \\
& =16,000 \text { BPD for } 0.1<t<2 \text { days } \\
& =15,500 \text { BPD for } 2<t<4 \text { days } \\
& =14,500 \text { BPD for } 4<t<6 \text { days } \\
& =14,000 \text { BPD for } 6<t<7 \text { days } \\
& =13,000 \text { BPD for } 7<t<10 \text { days }
\end{aligned}
$$

The above flow rates are generally larger than the full stream flow rates of figure 2. It should be noted that the presence of free gas in the flow stream would cause the flow meter to record erroneously high flow (and not low) rate. In the present study, we will assume that the brine flow rate for the Initial flow Test is indeed close 


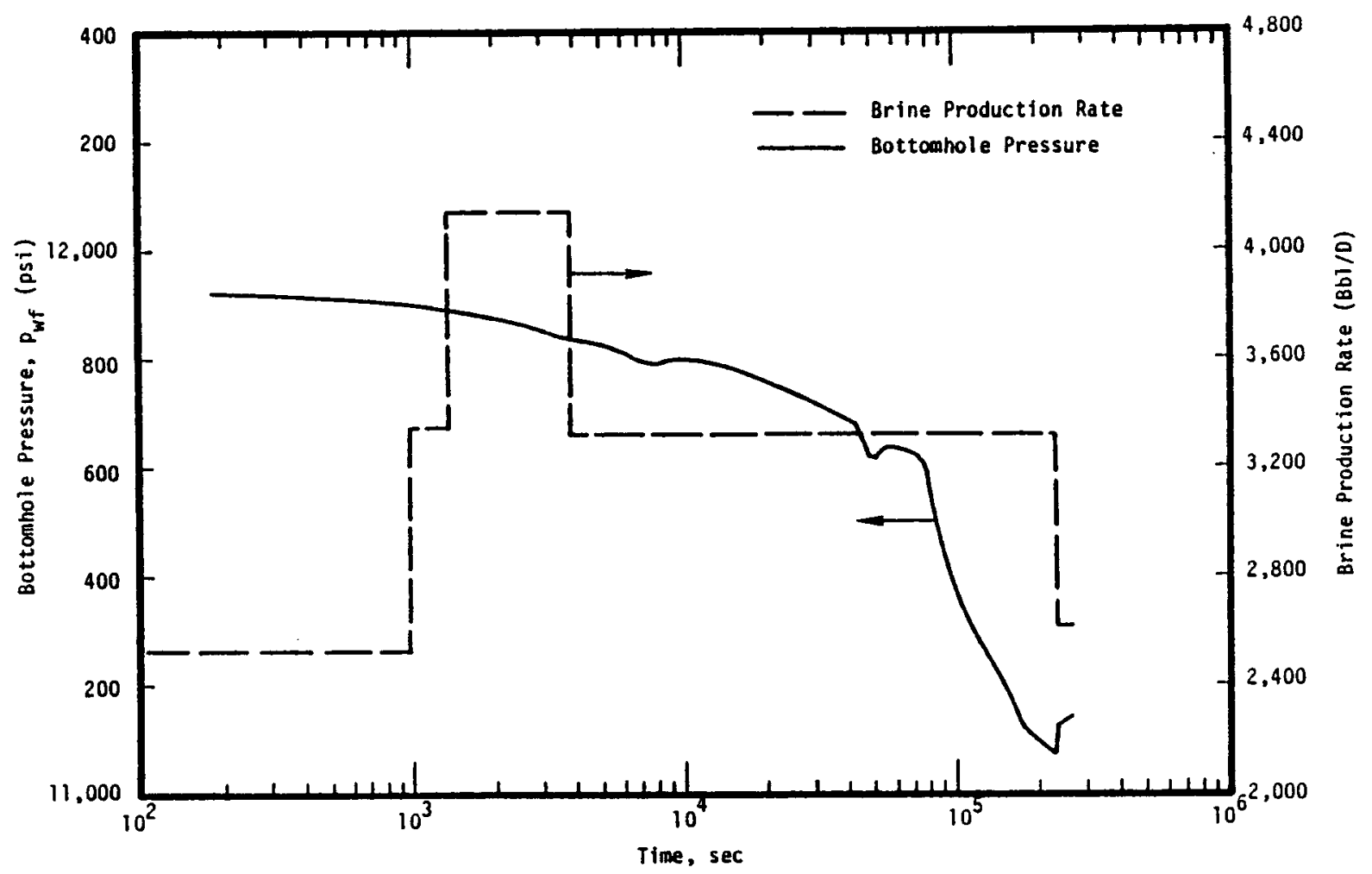

Figure 1. Pressure drawdown and brine production-rate for Initial Flow Test. Abcissa denotes time from the start of flow test at 18:18 hours on $6 / 19 / 1981$. 


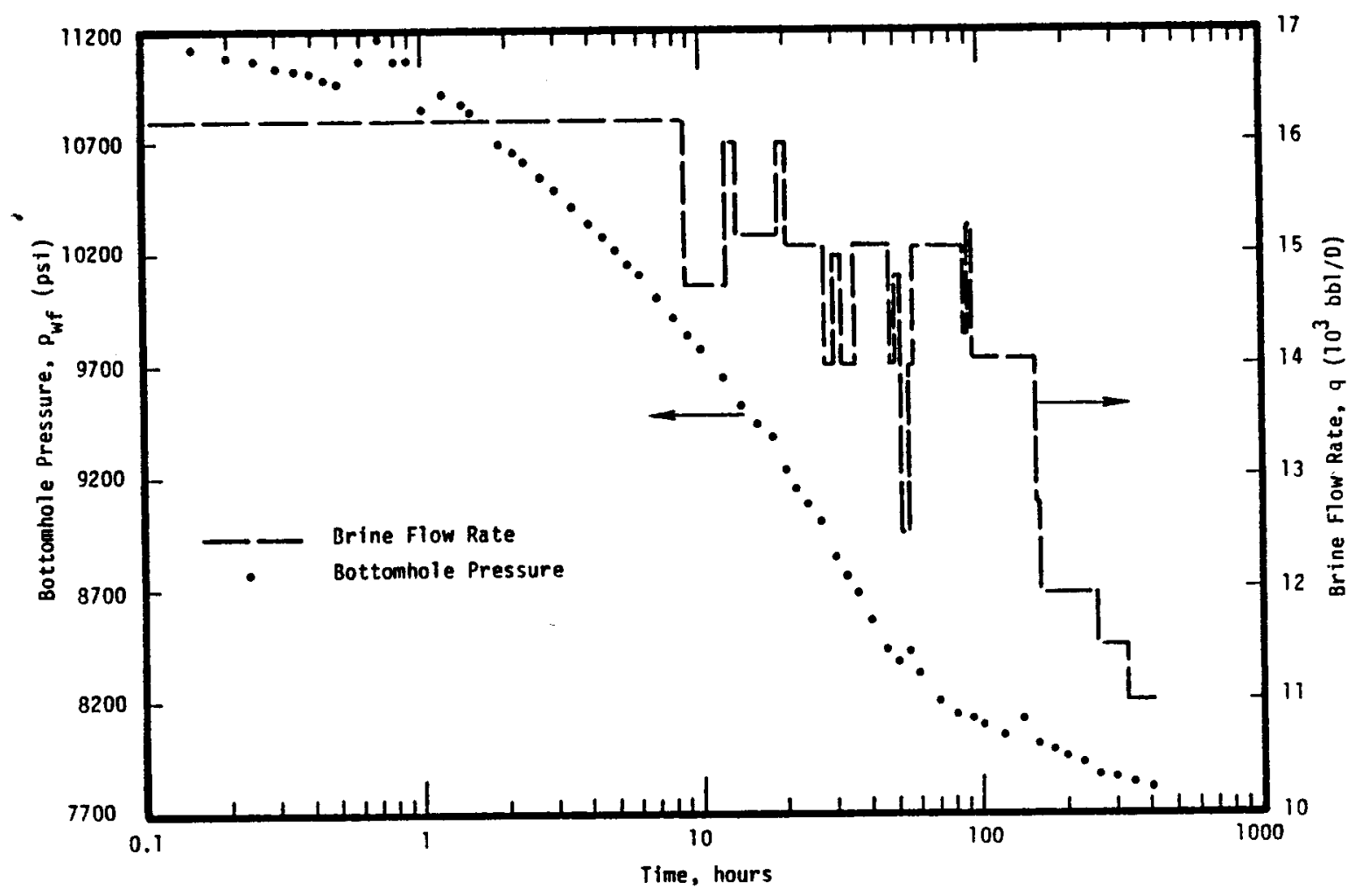

Figure 2. Pressure drawdown and brine production-rate data for Reservoir Determination Test. Abcissa denotes time from the start of the Reservoir Determination Test at 19:03 hours on $6 / 30 / 1981$. 
to that used by Gould, et al.; for the Reservoir Determination Test, we will take the brine flow rate to be approximately 85 percent of that of Gould, et al.

Gas production measurements during the two drawdown tests were made with concentric orifice plates. A value of 8.5-9 SCF/STB was reported during the Initial flow Test (see e.g., Garg [1981]), and a value of 13-15 SCF/STB was reported from the Reservoir Determination Test. These earlier gas/water ratios have now been determined to be erroneously low through a systematic study of both gas and brine measurements (L. Durrett, personal communication [1981]). It is now believed that the produced brine contains 23-27 SCF/B of gas. The latter value of gas-water ratio is close to the saturation limit predicted by the $S^{3}$ methane-brine equation-of-state $(\sim 23.7$ SCF/STB), and is approximately two-thirds of the saturation value $(\sim 34$ SCF/STB $)$ determined by Weatherly Laboratories from recombination studies. In the present work, it will be assumed that the reservoir brine is undersaturated with respect to gas content; the practical effect of the latter assumption is to ensure that the fluid stream at bottom hole conditions remains single-phase throughout the two drawdown tests.

The main purpose of this report is to analyze pressure transient data to evaluate formation parameters. Because of the uncertainties in brine flow rate data, we believe that the pressure drawdown data should be used with great caution in determining reservoir parameters. We will accordingly concentrate on the analysis of the buildup data obtained immediately following the Initial flow Test. It is appropriate to briefly discuss here the contents of the rest of this report. In Section II, we utilize conventional petroleum engineering/hydrology techniques to analyze buildup data to estimate permeability, skin factor, and any 
indications of faults/mobility changes in the perforated zone. Analysis of buildup data indicates that the MG-T/DOE AMOCO Fee No. 1 well penetrates a zone of relatively high permeability; this high permeability zone, however, extends to a radius of only about $200 \mathrm{ft}$ from the well. The far field permeability (i.e., for $r>200 \mathrm{ft}$ ) appears to be rather low.* No other reservoir boundaries/mobility changes can be identified. The present analysis is also compared to the previous analyses presented by Garg [1981] and Gould, et al. [1981]. The estimated parameters from the buildup analysis are employed in the $s^{3}$ geopressured-geothermal simulator (MUSHRM) to perform calculations to history match the observed drawdown/buildup pressures and flowrates (Section III). The computed drawdown pressures for the Initial flow Test show a rather poor agreement with the observations; it is believed that this disagreement is due to the uncertainties in the flow rate data. The calculated buildup pressures following the Initial Flow Test, and the simulated drawdown pressures for the Reservoir Determination Test are however, in excellent agreement with the observations.

* An alternate interpretation of the test data would be to assume that the flow to the well is restricted by the presence of two intersecting faults located at about 200-250 ft from the well. The test data does not, however, provide a sufficient basis for choosing between the two interpretations (i.e., low far-field permeability or intersecting faults). See also Section 2.2. 
-

$$
\bullet
$$

- 


\section{ANALYSIS OF BUILDUP DATA}

The MG-T/DOE AMOCO Fee No. 1 Well was flowed at varying rates from 18:18 hours on June 19, 1981 to 20:03 hours on June 22, 1981 for a total of 73.75 hours (Initial Flow Test). Bottom hole pressures were monitored continuously during the entire flow period. Subsequent to well shutin, pressure buildup was recorded for approximately 190.3 hours (i.e., from 20:03 hours on June 22, 1981 to 18:22 hours on June 30,1981 ) at which time the well was again put on production for the Reservoir Determination Test. As discussed in Section $I$, the recorded brine flow rate data are suspect; in the following, we will assume the following flow rates for the Initial Test:

$$
\begin{aligned}
q & =3000 \text { STB } / D \text { for } 0 \leq t \leq 21 \text { hour } s \\
& =3820 \text { STB } / D \text { for } 21 \leq t \leq 63.75 \text { hours } \\
& =2750 \text { STB } / D \text { for } 63.75 \leq t \leq 73.75 \text { hours }
\end{aligned}
$$

The above flow rate schedule is practically the same as that used by Gould, et al. [1981] but is at considerable variance from the one employed by Garg [1981]. The total brine volume produced during the Initial Test is taken in the present study (as it was in the earlier studies by Gould, et al. and Garg) to be 10,573 STB. Since the reservoir brine is undersaturated with respect to gas, it is likely that the flow stream, at bottom hole conditions, remained single phase liquid during drawdown. Consequently, classical single-phase methods should be sufficient for analyzing the pressure buildup data. 


\subsection{BUILDUP DATA ANALYSIS}

Analysis methods for buildup tests with widely varying flow rates before shutin are described by Earlougher [1977]. For infinite acting systems, a plot of shutin pressure $p_{W S}$ versus a reduced time

$$
\sum_{j=1}^{N}\left(a_{j} / a_{N}\right) \log \frac{t_{N}-t_{j-1}+\Delta t}{t_{N}-t_{j}+\Delta t}
$$

should yield a straight-line with slope $m$. Here $q_{j}$ is the flow rate during the time interval $t_{j-1}<t<t_{j}, t_{0}$ is $0, a_{N}$ is the final flow rate prior to shutin at $t=t_{N}$, and $\Delta t$ is the buildup time. Permeability $k$ and skin factor $s$ are given by:

$$
\begin{aligned}
& \frac{k h}{\mu}=\frac{162.6 q_{N} B}{m} \\
& S=1.151\left[\frac{p_{1} h r-p_{W f}}{m}-\log \frac{k}{b_{\mu} C_{T} r_{W}^{2}}+3.23\right]
\end{aligned}
$$

where

$$
\begin{aligned}
B= & \text { formation volume factor } \\
h= & \text { formation thickness, ft } \\
\mu= & \text { fluid viscosity, cp } \\
p_{W f}= & \text { final pressure before shutin, psi } \\
p_{1} h r= & \text { shutin pressure at } \Delta t \sim 1 \text { hour extrapolated from } \\
& \text { the straight-line, psi } \\
\phi= & \text { formation porosity } \\
r_{W}= & \text { well radius, ft } \\
C_{T}= & \text { total formation compressibility }\left(=((1-\phi) / \phi) \mathrm{C}_{\mathrm{m}^{+}}\right. \\
& \left.C_{f}\right), \text { psi }
\end{aligned}
$$




$$
\begin{aligned}
& c_{m}=\text { uniaxial formation compressibility, } \mathrm{ps}^{-1} \\
& c_{f}=\text { fluid compressibility, } p s i^{-1} .
\end{aligned}
$$

In the absence of measurements, we will assume that the uniaxial formation compressibility $c_{m}$ is of the order of $10^{-6}$ $p s i^{-1}$. With $c_{f}-3 \times 10^{-6} \mathrm{psi}^{-1}$ and $\phi=0.22$, we obtain for $\mathrm{C}_{\mathrm{T}}$ :

$$
C_{T}=\frac{1-0.22}{0.22} 10^{-6}+3 \times 10^{-6}-6.5 \times 10^{-6} \mathrm{psi}^{-1} .
$$

(For comparison purposes, we note that Gould, et al. use $C_{T}=4 \times$ $10^{-6} \mathrm{psi}^{-1}$.)

The buildup pressure data are plotted as a function of reduced time (Eq. (1)) in Figures 3 and 4 . It can be seen from Figures 3 and 4 that two straight lines can be drawn through the buildup data; these straight-lines have slopes of $31.5 \mathrm{psi} / \mathrm{cycle}$ and $429 \mathrm{psi} / \mathrm{cycle}$ respectively. The first straight line segment (slope $\approx 31.5$ psi/cycle) yields for near wellbore permeability:

$$
k=\frac{162.6 q_{N} B \mu}{m h}=\frac{162.6 \times 2750 \times 1.041 \times 0.296}{31.5 \times 27} \approx 162 \mathrm{md}
$$

(The $S^{3}$ equation-of-state data yields $\mu=0.296 \mathrm{cp}$ at reservoir conditions. This value of $\mu$, however, is at considerable variance from the one $(\mu=0.395 \mathrm{cp})$ reported by Weatherly Laboratories. Since viscosity $\mu$ only occurs in the combination $k / \mu$ in all reservoir equations, it is immaterial as to which value of viscosity $\mu$ is employed in the analysis as long as the ratio $k / \mu$ is preserved. We will return to this question in the next section.) With $p_{1 \mathrm{hr}}=11,309.5 \mathrm{psi}$ and $p_{\mathrm{wf}}=11,141 \mathrm{psi}$, we obtain for skin factor s:

$$
S=1.151\left[\frac{p_{1 h r}-p_{w f}}{m}-\log \frac{k}{\phi \mu C_{T} r_{w}^{2}}+3.23\right] \approx-1.48
$$




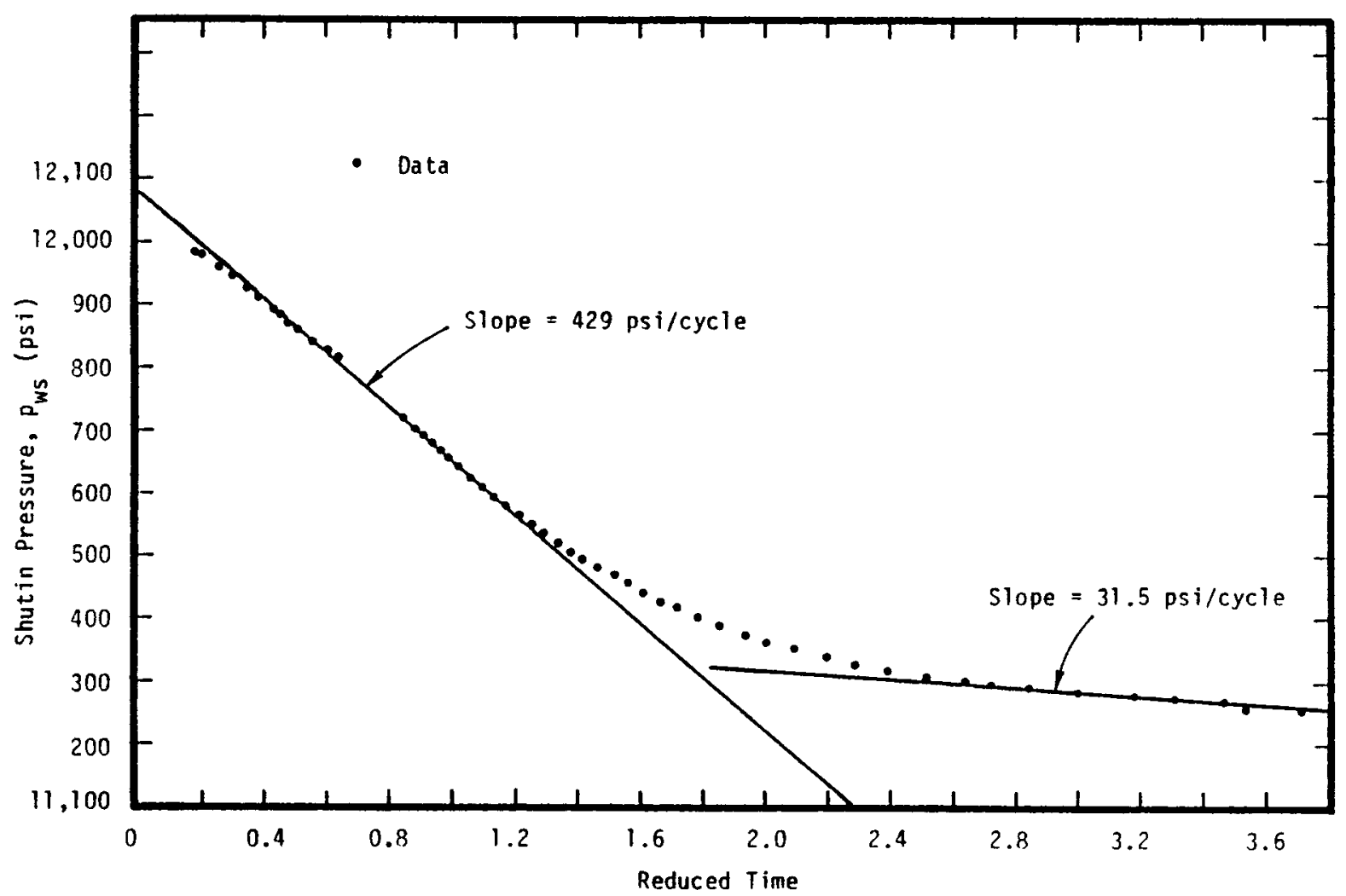

Figure 3. Buildup pressure data following Initial Flow Test. 


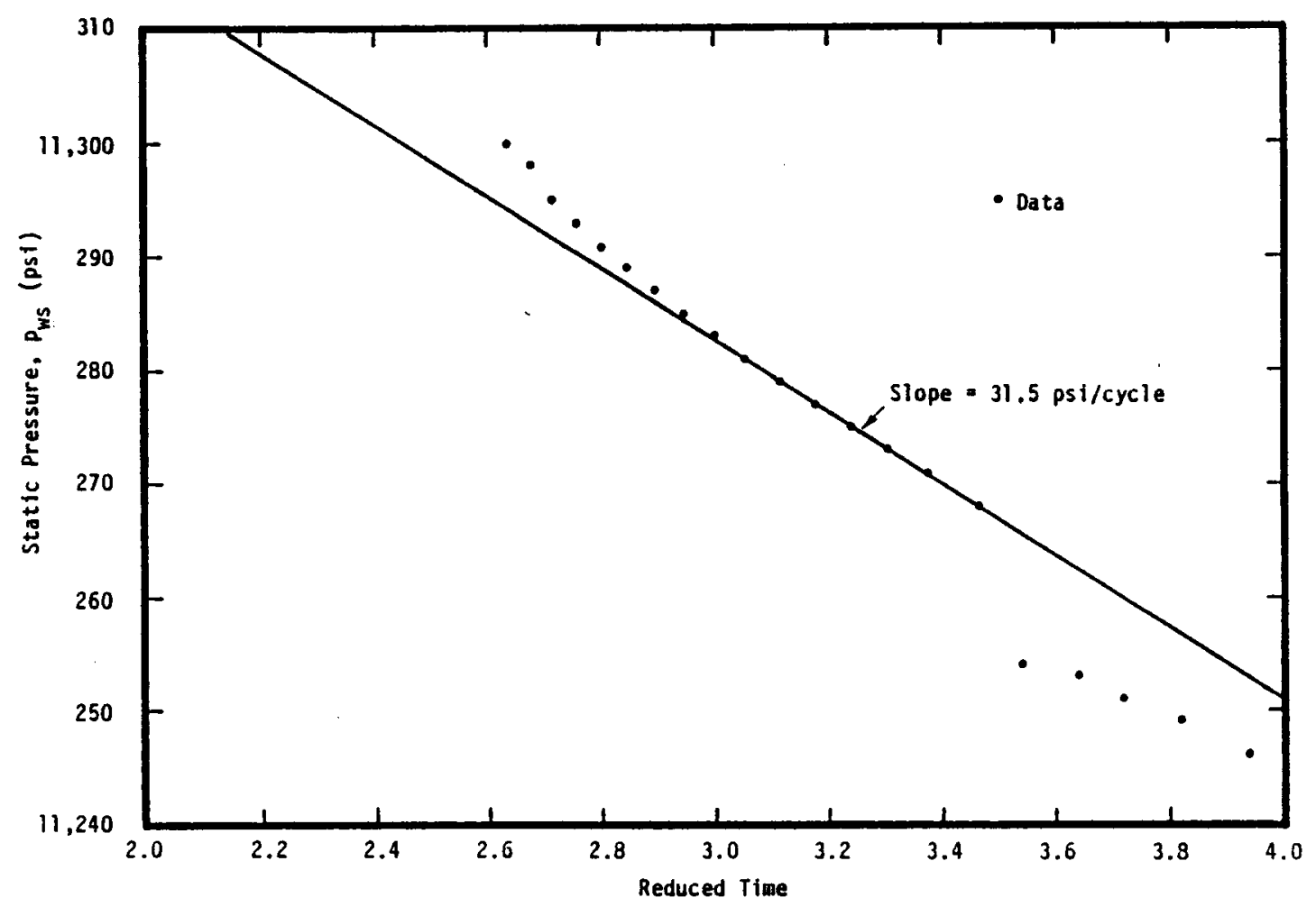

Figure 4. Early-time buildup data following Initial flow Test. 
The pressure buildup data start deviating from the first straight1 ine segment at approximately $\Delta t \simeq 0.15$ hours. The radius investigated by the buildup test at this point in time is approximately given by (see Earlougher [1977]):

$$
\begin{aligned}
r_{i n v} & =\left(\frac{0.00105 k \Delta t}{\phi C_{T}}\right)^{1 / 2} \\
& =\left(\frac{0.00105 \times 162 \times 0.15}{0.22 \times 0.296 \times 6.5 \times 10^{-6}}\right)^{1 / 2} \approx 245 \mathrm{ft}
\end{aligned}
$$

This implies that the permeability obtained from the first straight-line segment applies within a circular region centered at the well of radius ( $r_{\text {trans }}$ ) approximately equal to $245 \mathrm{ft}$. In the following, we will present an alternative procedure for estimating $r_{\text {trans }}{ }^{\circ}$

The second straight-line segment has a slope of $429 \mathrm{psil}$ cycle.* This yields for "far-field" permeability:

$$
k=\frac{162.6 \times 2750 \times 1.041 \times 0.296}{429 \times 27}=11.9 \mathrm{md}
$$

We now assert that the effect of the high permeability zone near the wellbore can be represented by an equivalent skin $s_{e q}$. With $p_{1 h r}=11,157.5$ psi (extrapolated from the second straight-line segment) and $p_{w f}=11,141$ psi, we obtain for $s_{e q}$ :

* It should be noted that the second straight-line segment can also be interpreted to indicate the presence of two intersecting faults located at about $200-250 \mathrm{ft}$ from the wel1. The graben angle $\alpha$ is given by: $\alpha=360 \times$ slope of 1 st straight-line segment/slope of 2 nd straight-line segment $=360$ $x 31.5 / 429,=26.40$. We shall return to this question in Section 2.2 . 


$$
\begin{aligned}
s_{e q} & =1.151\left[\frac{11157.5-11141}{429}\right. \\
& \left.-\log \frac{11.9}{0.22 \times 0.296 \times 6.5 \times 10^{-6} \times(5.5 / 24)^{2}}+3.23\right] \approx-6.28 .
\end{aligned}
$$

The equivalent skin factor seq is related to "near wellbore" permeability $k_{1}$, "far field" permeability $k_{2}$, transition radius $r_{\text {trans }}$, and wellbore radius $r_{w}$ as follows:

$$
k_{2} / k_{1}=\frac{s_{\text {eq }}}{\ln \left(\frac{r_{\text {trans }}}{r_{w}}\right)}+1
$$

With $k_{1}=162 \mathrm{md}, k_{2}=11.9 \mathrm{md}, \mathrm{s}_{\text {eq }}=-6.28$ and $r_{w}=$ $(5.5 / 24) \mathrm{ft}$, we obtain for $r_{\text {trans }}$ :

$$
r_{\text {trans }}=\exp \left[\frac{s_{e q}}{\left(k_{2} / k_{1}-1\right)}+\ln r_{w}\right] \approx 201 \mathrm{ft}
$$

The above value for $r_{\text {trans }}(\sim 200 \mathrm{ft})$ is of the same order as that calculated on the basis of the observed pressure deviations from the first straight-line segment.

To summarize, the principal results of the preceding analys is are:

1. The near wellbore permeability is about $162 \mathrm{md}$, and applies within a radius of approximately 200 ft from the wellbore. The far-field permeability (radius > $200 \mathrm{ft}$ ) is, however, only about $11.9 \mathrm{md}$.

2. The well is slightly stimulated (skin factor s $-1.48)$. The negative skin factor may represent the presence of a very permeable zone in the immediate vicinity of the wellbore. 
3. No reservoir boundaries can be inferred from the buildup data.

4. The formation parameters obtained from the present analysis differ but little from those given by Garg [1981].

2.2 COMPARISON WITH THE ANALYSIS OF GOULD, ET AL.

Gould, et al. [1981] have interpreted the two drawdown tests; they did not, however, attempt to analyze the buildup data. Since Gould, et al.'s model differs in some respects from the analysis presented in Section 2.1, we will now briefly review their model. Figure 5 shows the early time drawdown data from the Initial flow Test. Two straight-lines with slopes $m_{1}=24$ psi/cycle and $m_{2}=$ 43 psi/cycle can be drawn through the drawdown data for $3.5 \leq t \leq 10$ min; note that the first straight-line segment lasts for less than 1.5 minutes ( $3.5 \leq t \leq 5$ minutes). In their paper, Gould, et al. quote slightly different values for $m_{1}, m_{2}$ and $p_{1} \mathrm{hr}\left(m_{1}=\right.$ $22 \mathrm{psi}$ cycle, $m_{2}=44 \mathrm{psi} /$ cycle and $\left.p_{1} \mathrm{hr}=11,896 \mathrm{psi}\right)$. With $\mathrm{m}$ $=22 \mathrm{psi} / \mathrm{cycle}, q=3000 \mathrm{bbl} / \mathrm{D}, h=27 \mathrm{ft}, \mathrm{B}=1.046, \phi=0.23$ and $C_{T}=3.23 \times 10^{-6} \mathrm{psi}^{-1}$, Gould, et al. [1981] obtain the following values for mobility $\mathrm{kh} / \mathrm{\mu}$ and skin factor s:

$$
\begin{aligned}
& \frac{k h}{\mu}=\frac{162.6 q B}{m}=\frac{162.6 \times 3000 \times 1.046}{22} \approx 23,200 \frac{\mathrm{md} f t}{c p} \\
S & =1.151\left[\frac{p_{i}-p_{1} h r}{m}-\log \frac{k h}{\phi \mu c_{T} r_{W}^{2}}+3.23\right] \\
& =1.151\left[\frac{12053-11896}{22}\right. \\
& \left.-\log \frac{23200}{0.23 \times 27 \times 3.23 \times 10^{-6}(5.5 / 24)^{2}}+3.23\right]=0.027
\end{aligned}
$$




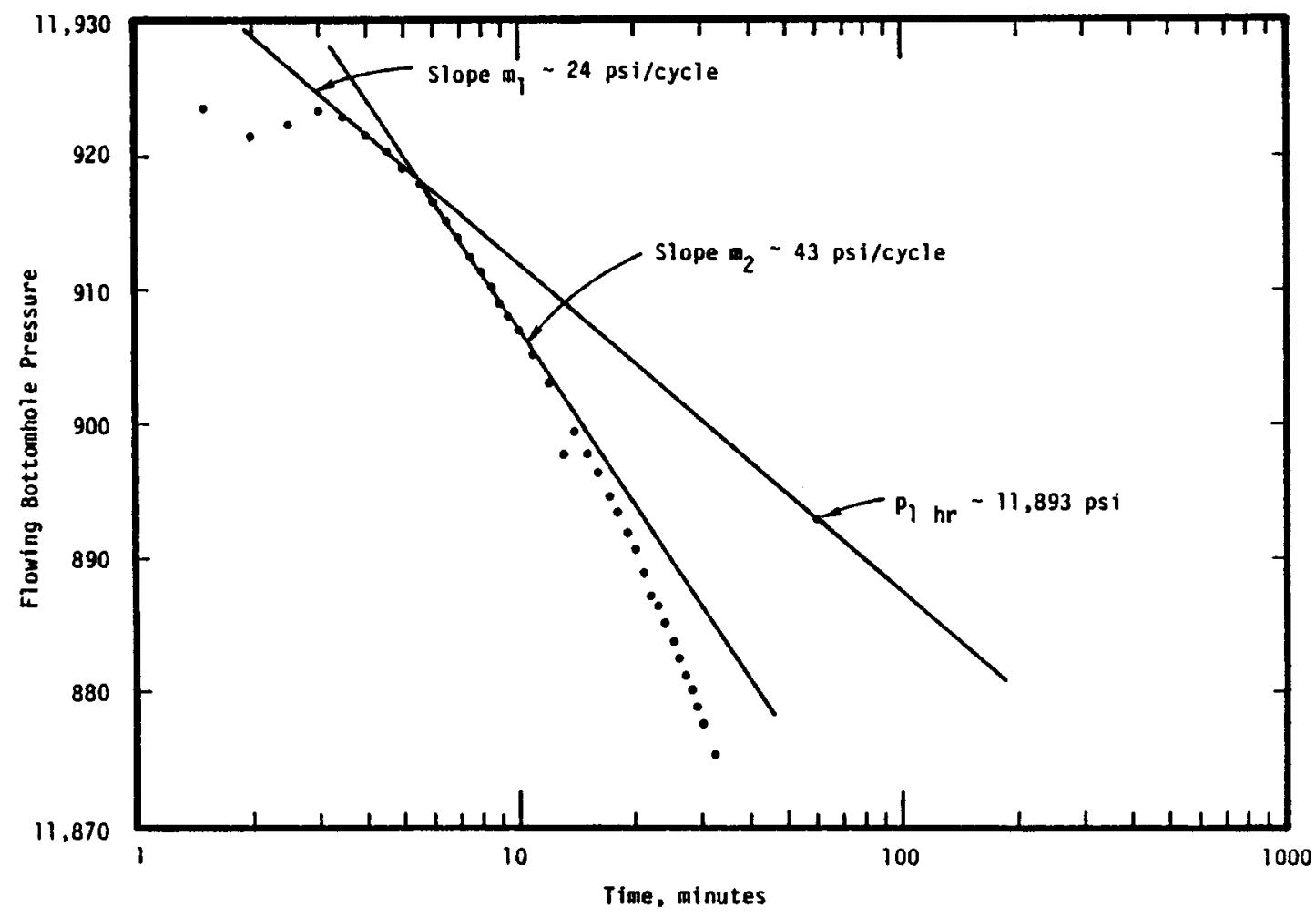

Figure 5. Early-time pressure drawdown data (Initial Flow Test). 
The near doubling of slope at $t=5 \min (\approx 0.0035$ days $)$ is interpreted as a permeability barrier. The calculated distance to the permeability barrier is:

$$
\begin{aligned}
r_{d} & =\left(\frac{0.00105 k h t}{\omega C_{T} h}\right)^{1 / 2} \\
& =\left(\frac{0.00105 \times 23200 \times 0.0035 \times 24}{0.23 \times 3.23 \times 10^{-6} \times 27}\right)^{1 / 2}-320 \mathrm{ft}
\end{aligned}
$$

Additional permeability barriers are similarly inferred at $452 \mathrm{ft}$ and $1753 \mathrm{ft}$. To obtain permeability $k$ from mobility $\mathrm{kh} / \mu$, we require viscosity $\mu$. With $\mu \simeq 0.395 \mathrm{cp}$ (i.e., value reported by Weatherly Laboratories), Gould, et al. obtain

$$
k=\frac{23,200 \times 0.395}{27}-339 \mathrm{md}
$$

(By comparison $\mu=0.3 \mathrm{cp}$ yields $k \simeq 258 \mathrm{md}$.)

In their computer simulation of the drawdown data, Gould, et al. assume somewhat different parameters than those obtained from the above described analysis. More specifically, the following parameters were utilized in their computer simulations:

$$
\begin{aligned}
& \text { Permeability, } k=260 \mathrm{md} \\
& \text { Porosity, } \phi=0.2 \\
& \text { Formation thickness, } h=27 \mathrm{ft} \\
& \text { Total formation compressibility, } c_{T}=4 \times 10^{-6} \mathrm{psi}^{-1} \text {. }
\end{aligned}
$$

Although it is not explicitly stated, it appears that Gould, et al. utilized $\mu=0.395 \mathrm{cp}$ in their history match of the drawdown data. (It is interesting to note that in order to preserve the ratio $k / \mu$, a value of $\mu=0.3 \mathrm{cp}$ should have been employed with $k \simeq 260 \mathrm{md}$.) Gould, et al. also assume that two intersecting major faults exist only $250 \mathrm{ft}$ from the well (see Figure 6). 


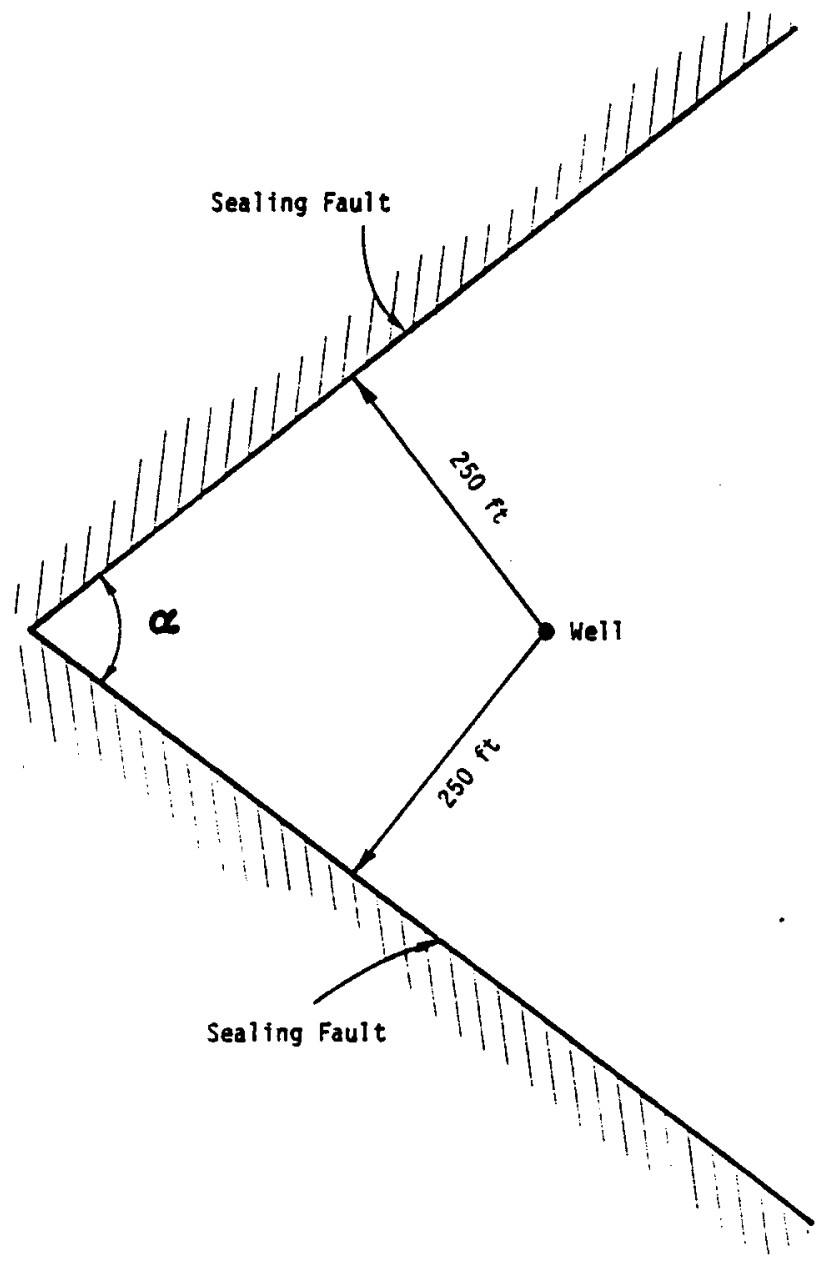

Figure 6. Well/fault configuration employed by Gould, et al. [1981]. 
To history-match the Initial flow Test, a graben angle $\alpha=60^{\circ}$ was taken. Our attempts to reproduce the simulation results given in Gould, et al. [1981] were unsuccessful. More specifically, we found it impossible to reproduce the extremely sharp drop in the flowing pressure (see Figure 1 ) observed at $t \sim 0.9$ days with the reservoir model properties of Gould, et al. (We have been given to understand that the original computer files ( $T$. Gould, persona] communication [1981]) used to generate the results in Gould, et al. are no longer available; consequently, it is impossible to establish the reasons for our failing to reproduce the results of Gould, et al.)

In order to history match the drawdown data from the Reservoir Determination Test, Gould, et al. found it necessary to reduce the graben angle $\alpha$ to $26^{\circ}$. Although we did not attempt to reproduce the results of Gould, et al. for this drawdown test, it is interesting to note that a graben angle of $\alpha=26^{\circ}$ implies that the well drains only $1 / 13.8$ of a radial reservoir; by comparison the analysis presented in Section 2.1 shows that the "far-field" reservoir permeability $k_{2}(\approx 11.9 \mathrm{md})$ is only $1 / 13.6$ of "near-field" reservoir permeability $k_{1}(=162 \mathrm{md})$.

In Appendix B, we compare pressure drawdown solutions for a single well producing from (1) a reservoir system consisting of two concentric regions with differing permeabilities $k_{1}$ and $k_{2}$ $\left(k_{1} / k_{2}=12\right)$, and (2) a reservoir region bounded by two faults with a graben angle $\alpha$ of $30^{\circ}\left(\alpha=360 \times k_{2} / k_{7}\right)$. A value of $\alpha=30^{\circ}$ is used to facilitate analysis. Both the solutions (Appendix $B$ ) exhibit identical behavior at very early times; at late times, the pressure drawdown curves asymptote to two parallel straight lines separated by approximately one-fifth of a $\log$ cycle. The latter clearly implies that the test data from MG-T/DOE AMOCO FEE No. 1 
for choosing between the present model and that presented by Gould, et al. To put it somewhat differently, the existing test data from the subject well does not lead to a unique solution for the reservoir parameters.

To summarize, we note that both the present model and the one presented by Gould, et al. imply that the reservoir character changes at a distance of about $200-250 \mathrm{ft}$ from the wellbore. Gould, et al. model the reservoir behavior by postulating the existence of two intersecting faults at $250 \mathrm{ft}$ from the well; the analysis of Section 2.1 implies reduced formation permeability at about $200 \mathrm{ft}$ from the well. The reduction in formation permeability (a factor of 13.6) given in Section 2.1 is essentially the same as the reduction in flow angle a (a factor of 13.8) required in the model of Gould, et al. for the Reservoir Determination Test. Further comparison of the two models is, however, not practical due to the various unresolved uncertainties in the parameters utilized in the simulations performed by Gould, et al. 
• 


\section{HISTORY-MATCH CALCULATIONS}

We will now employ the formation properties derived from the buildup data (Section 2.1) in the MUSHRM reservoir simulator to match the observed drawdown/buildup pressure data. For simulation purposes, the reservoir is assumed to be a right circular cylinder with height $h=27 \mathrm{ft}$ and radius $R=24,840 \mathrm{ft}$. The radius $R$ is chosen sufficiently large that no signal reaches the outer boundary of the reservoir for the drawdown/buildup times of interest.* The reservoir is represented by a 50 zone $\left(\Delta r_{1}=\Delta r_{2}=\ldots, \Delta r_{10}=\right.$ $50 \mathrm{ft} ; \Delta r_{11}=1.1 \Delta r_{10}, \Delta r_{12}=1.1 \Delta r_{11}, \ldots, \Delta r_{50}=1.1$ $\left.\Delta r_{49}\right)$ radial grid. The outer boundary is assumed to be impermeable and insulated; this boundary condition does not affect the result. The production well is located at the geometric center of the first grid block.

The reservoir rock is taken to be a sandstone with the following properties:

Rock grain density, $\rho_{r}=\frac{165.4}{\left.10^{3} \mathrm{~kg} / \mathrm{m}^{3}\right)} \mathrm{ft} / \mathrm{ft}^{3}(\sim 2.65 \times$

Initial porosity, $\phi_{0}=0.22$

Rock grain specific heat, $C_{v r}=0.23 \mathrm{Btu} / \mathrm{lbm}-{ }^{\circ} \mathrm{F}(=$

Initial permeability, $k_{0}=162 \mathrm{md}$ for $0 \leq r \leq 200 \mathrm{ft}$

$=11.9 \mathrm{md}$ for $r^{-} \geq 200 \mathrm{ft}$

Skin factor, $s=-1.48$

\# This does not in any way imply that we consider the reservoir to be circular in shape. The shape and location of the outer boundary simply cannot be determined on the basis of the presently available test data. 
A drop in pore pressure causes a reduction in porosity $\phi$ and the permeability $k$. The instantaneous porosity $\phi$ and permeability $k$ are given by the following relations:

$$
\begin{aligned}
\frac{\partial \phi}{\partial t} & =(1-\phi) c_{m} \partial p / \partial t \\
k & =k_{0}\left(\phi / \phi_{0}\right)^{3}\left(\frac{1-\phi_{0}}{1-\phi}\right)^{2}
\end{aligned}
$$

where

$$
\begin{aligned}
& p=\text { fluid pressure } \\
& t=\text { time. }
\end{aligned}
$$

Although in the present case the pore fluid remains singlephase (liquid), we give in Table 1 relative permeabilities for water/ gas to illustrate the effects of the presence of any free gas in the pores. These relative permeabilities are based on measurements reported by Roberts [1980] on several cores obtained from the Pleasant Bayou (Brazoria County, Texas) geopressured wells. Table 1 shows that the gas phase remains essentially immobile for $S_{g} \leq 0.235$ (= residual gas saturation), and the liquid-phase relative permeability declines dramatically with small amounts of free gas in the pores.

Table 1

RELATIVE PERMEABILITIES

\section{Liquid Relative}

Free Gas Saturation $\left(S_{g}\right)$ Permeability $\left(k_{r w}\right)$
Gas Relative Permeability $\left(\mathrm{k}_{\mathrm{rg}}\right)$

$\begin{array}{ll}0 & 1 \\ 0.005 & 0.71 \\ 0.1 & 0.49 \\ 0.235 & 0.12 \\ 1 & 0\end{array}$

0
$10^{-4}$
$2 \times 10^{-4}$
$5 \times 10^{-4}$
1


The reservoir fluid is a brine, partially saturated with methane, with a dissolved solids mass fraction of $S=0.1487$. (This corresponds to a TDS of approximately $165,000 \mathrm{ppm}$ at the standard conditions.) The initial pore pressure and temperature at a depth of $15,400.5 \mathrm{ft}$ are $p=12,082$ psi $(=833.02$ bars $)$ and $T=299^{\circ} \mathrm{F}(\approx$ $148.33^{\circ} \mathrm{C}$ ) respectively. The reservoir is produced by a single well of diameter $5.5 \mathrm{in.}$. In the following, all pressures are referred to the $15,337 \mathrm{ft}$ datum; the initial pressure at this datum is 12,053 psi $(\approx 831.03$ bars $)$.

Figure 7 compares the calculated bottom hole pressures (Initial flow Test) with the observed drawdown pressures, and with the old match by Garg [1981]. The production history imposed in the present simulation is also plotted in Figure 7 . The use of the production history of Figure 7 results in a much better pressure match than that obtained in Garg [1981]. It is important to realize that the correct specification of production history (even when the total production is kept unchanged) is crucial for obtaining a good pressure match. The agreement between the computed pressures (present case) and the measured pressures could no doubt be further improved by varying the production rate data.

The observed and calculated buildup pressures following the Initial Flow Test (present case and the old match by Garg [1981]) are compared in Figure 8. In general, results of present simulation agree closely with both the measured pressures and the old history match. The change in the production rate data is seen to have little influence on the calculated buildup pressures.

Finally, in Figure 9 we compare the calculated and measured drawdown pressures for the Reservoir Determination Test. The production history imposed is also shown in Figure 9. The flow rate is assumed to be 16,000 STB/D for the first 33 minutes; pressure 


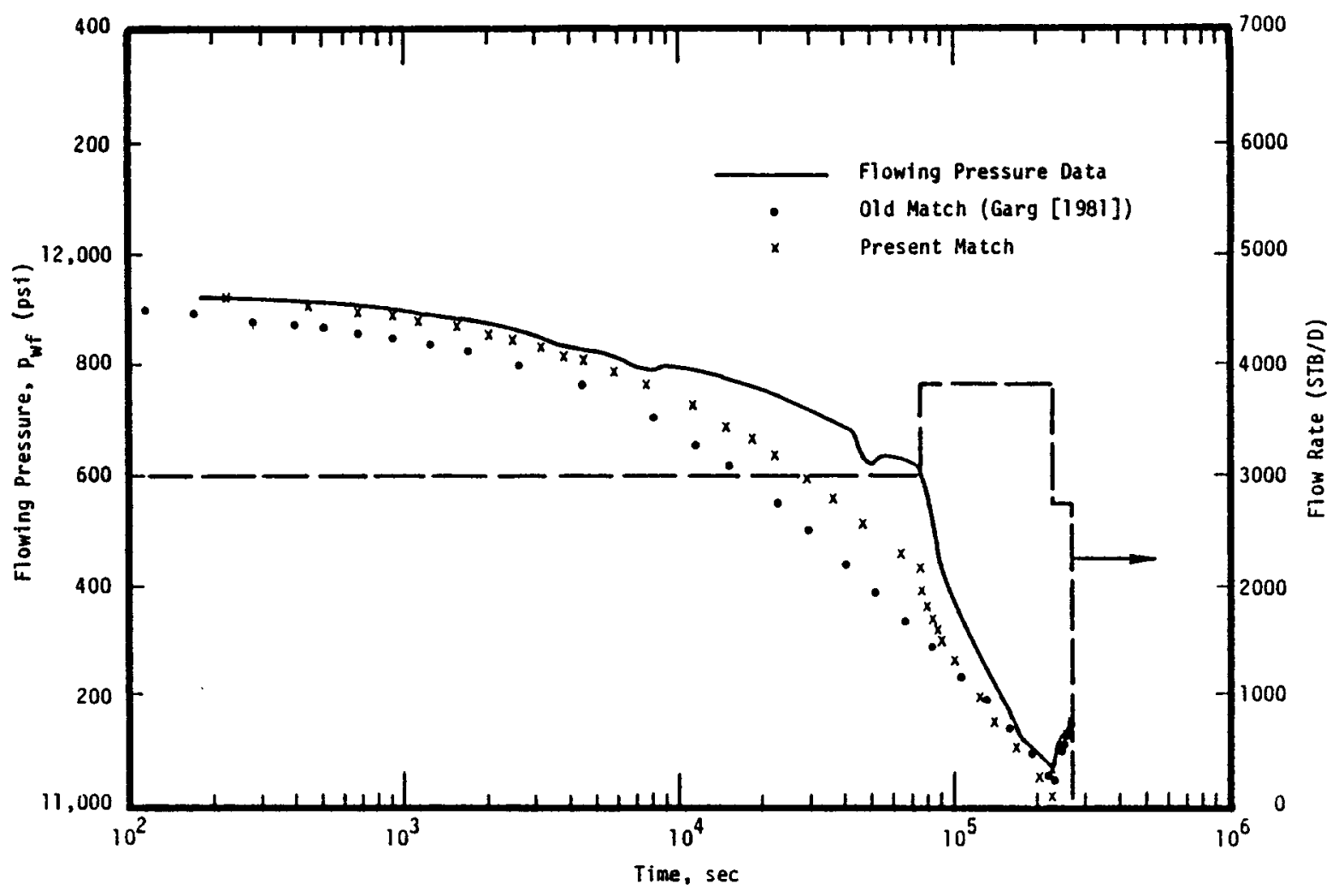

Figure 7. Comparison of calculated flowing pressures with measured flowing pressures for Initial Flow Test of MGT-DOE AMOCO Fee No. 1 Well. Abcissa denotes time from the start of the Initial Flow Test. 


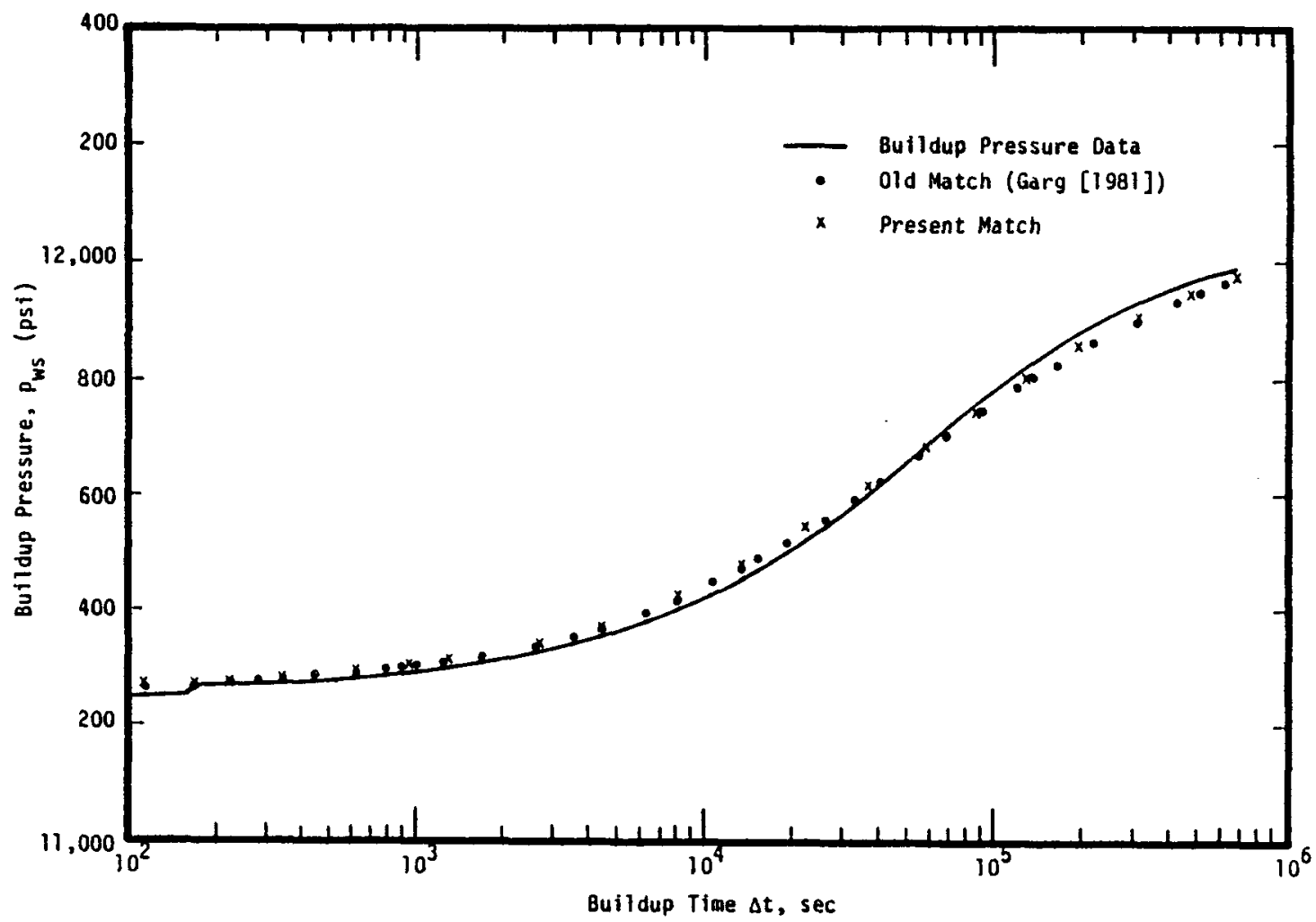

Figure 8. Comparison of calculated buildup pressures with measured buildup pressures for Initial flow Test of MGT-DOE AMOCO Fee No. 1 Well. Abcissa denotes time from the start of shutin at the end of the Initial flow Test. 


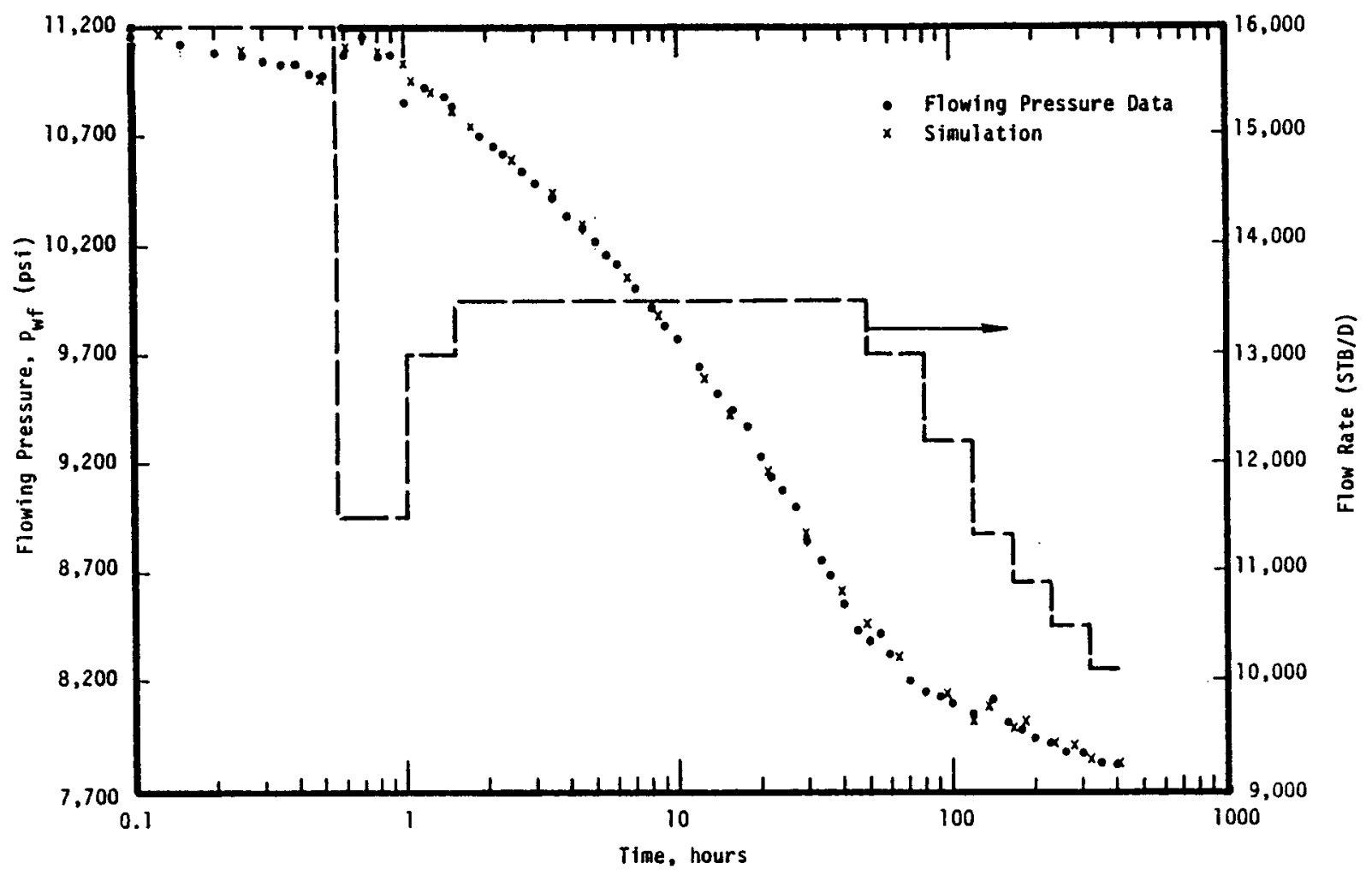

Figure 9 Comparison of calculated and measured bottomhole pressures for the Reservoir Determination Test. Abcissa denotes time from the start of this flow test. 
data indicate that flow rate was drastically reduced at this time. For $1.5 \mathrm{hr}<t<48 \mathrm{hr}$, the flow rate is taken to be constant $(\sim 13,500 \mathrm{STB} / 0)$. The flow rates imposed in the simulation are approximately 90 percent of the full stream measured flow rates (Note that the rates used by Gould, et al. are generally higher than the measured full stream flow rates.). After the first 48 hours, the flow rates are gradually reduced to a final rate of 10,100 STB/D at the conclusion of the Reservoir Determination Test. As may be seen, the simulated pressure data are in excellent agreement with the measurements.

On the basis of the satisfactory match between the observed and simulated pressure data, it is reasonable to conclude that (1) no reservoir boundaries (apart from the mobility transition at 200 $\mathrm{ft}$ ) have been encountered during either the Initial flow Test or the Reservoir Determination Test, and (2) the inability of the reservoir to sustain high flow rates (say over $10,000-15,000$ STB/D) is due to poor formation permeability.*

* This interpretation differs from the one given by Gould, et al. who ascribe the inability of the reservoir to sustain high flow rates to the presence of barriers close to the well. See also Section 2.2. 
- 


\section{CONCLUDING REMARKS}

Analysis of buildup data from the Initial flow Test indicates that the MG-T/DOE AMOCO Fee No. 1 Well penetrates a zone of relative high permeability ( $162 \mathrm{md})$; this high permeability zone, however, extends to a radius of only $200 \mathrm{ft}$ from the wellbore. The far field permeability (i.e., for $r>200 \mathrm{ft}$ ) appears to be rather low $(\sim 11.9$ md). The reservoir simulator MUSHRM together with the formation parameters inferred from the buildup data were employed to successfully history match the observed drawdown (Initial flow Test and the Reservoir Determination Test) and buildup pressure data. It appears that no reservoir boundaries were encountered during the test period. The inability of the well to sustain high production rates $(>-15,000 \mathrm{Bb} / / \mathrm{D})$ during the Reservoir Determination Test is thus believed to be due to the poor far-field formation permeability of the perforated sand interval (fifth sand)*. In any future testing of this well, consideration should be therefore given to perforating additional sands.

* An alternate interpretation of the test data would be to assume that the flow to the well is restricted by intersecting faults (graben angle $\sim 26^{\circ}$ ) located at about $200-250 \mathrm{ft}$ from the well. See Section 2.2 for a detailed discussion of this question. 
-

- 


\section{REFERENCES}

DURRETT, L. R. and C. 0. Durham, Jr., "Geopressured - Geothermal Test Plan: MG-T/DOE AMOCO Fee No. 1 Well, Sweet Lake Prospect, Cameron Parish, Louisiana," Magma-Gulf Technadril, Houston, Texas, Report 1981.

EARLOUGHER, R. C., Jr., Advances in Well Test Analysis, Monograph No. 5, Society of Petroleum Engineers of AIME, Dallas, Texas, 1977.

GARG, S. K., "Analys is of Initial Flow Data from MG-T/DOE AMOCO Fee No. I Well," S-Cubed, La Jolla, California, Report DOE/NV/10150-2, 1981.

GOULD, T. L. , C. B. Kenner, and J. D. Cl ark, "Reservoir Engineering and Computer Model Analyses of Flow Tests on the Miogypsinoides Sandstone: Sweet Lake Geothermal - Geopressured Project," Proceedings Fifth Geopressured - Geothermal Energy Conference, pp. 317-323, Baton Rouge, Louisiana, October 13-15, 1981.

HURST, W., "Interference Between 0il Fields," Transactions AIME, Vol. 219, pp. 175-192, 1960.

PRITCHETT, J. W., S. K. Garg, M. H. Rice and T. D. Riney, "Geopressured Reservoir Simulation," S-Cubed, La Jolla, California, Report SSS-R-79-4022, 1979.

ROBERTS, B. W., "Relative Permeability Measurements of Texas Gulf Coast Sandstones at Low Free Gas Saturations," Center for Earth Sciences and Engineering - Division for Rock Mechanics, The University of Tesas at Austin, Report No. UT 80-2, 1980. 
-

- 


\section{APPENDIX A \\ MG-T/DOE AMOCO Fee No. 1 We1l: Test Data Notes}

I. Completed Interval: $15,387-15,414 \mathrm{ft}$

Net Sand Thickness: $27 \mathrm{ft}$

Mean Reservoir Depth: 15,400.5 ft

Rock Porosity $\phi: 0.22$

Well Radius $r_{w}=2.75$ in $(0.06985 \mathrm{~m})$

II. Since all pressures are measured at $15,337 \mathrm{ft}$ datum, this datum is employed in most of the calculations in this report. Pressures at a datum other than $15,337 \mathrm{ft}$ are calculated by using a correction factor of $0.46 \mathrm{psi} / \mathrm{ft}$.

III. Initial Pressure Data:

$p_{i}(15,337 \mathrm{ft}$, measured $)=12,053 \mathrm{psi}(\approx 831.03$ bars $)$

$p_{i}(15,400.5 \mathrm{ft}$, calculated $)=12,082$ psi $(\approx 833.02$ bars $)$

IV. Initial Reservoir Conditions $(15,400.5 \mathrm{ft}$, datum):

$p_{j}=12,082$ psi $(=833.02$ bars $)$

$T_{i}$ (measured $)=299^{\circ} \mathrm{F}\left(\simeq 148.33^{\circ} \mathrm{C}\right)$

$S$ (salinity by mass) $=0.1487$

$C$ (methane content): see below.

v. At standard conditions $\left(p=14.7 \mathrm{psi}, T=60^{\circ} \mathrm{F}\right.$ ) with $\mathrm{S}=$ 0.1487 , the $s^{3}$ equation-of-state gives

$\rho_{\text {Brine }}=1.1088 \mathrm{gm} / \mathrm{cm}^{3} \quad(=176.287 \mathrm{~kg} / \mathrm{STB})$

Total Dissolved Solids $=S \rho_{\text {Brine }} \simeq 165,000 \mathrm{ppm}$

Specific Volume of Methane $=52.0 \mathrm{SCF} / \mathrm{kg}$ 
VI. Methane Content of Resevoir Fluids

Given $P_{j}, T_{i}$ and $S$ (see IV above), the methane mass fraction at saturation a sat may be calculated by using the $s^{3}$ equation-of-state data. This yields:

$\alpha_{\text {sat }}=0.257465 \times 10^{-2}$

Thus, at saturation we have:

$\frac{\text { SCF of Methane }}{\text { STB }} \simeq \frac{52.00 \times 0.257465 \times 10^{-2}}{5.6726 \times 10^{-3}\left(1 .-0.257465 \times 10^{-2}\right)} \simeq 23.7$

For comparison purposes, Weatherly Laboratories reports (on the basis of recombination studies) the gas-brine ratio at saturation to be around 34 SCF/STB. The brine produced had a gas content of 23-27 SCF/B ( 2/3 of the saturation value obtained by Weatherly Laboratories). In the present work, it is assumed that the reservoir brine is undersaturated with respect to gas in accordance with the above discussed data.

VII. Reservoir Fluid Density, Pressure Gradient and Formation Volume Factor

With $p_{i}=12,082 \mathrm{psi}, T_{i}=299^{\circ} \mathrm{F}$ and $S=0.1487$ the $\mathrm{S}^{3}$ equation-of-state data yields:

Initial Fluid Density, $\rho_{j}=1.0656 \mathrm{gm} / \mathrm{cm}^{3} \quad(=169.421$ $\mathrm{kg} / \mathrm{bb} 1$ )

Pressure Gradient $=0.462 \mathrm{psi} / \mathrm{ft}$

Formation Volume Factor $B=176.287 / 169.421 \approx 1.041$ 
VIII. At reservoir conditions, the $S^{3}$ equation-of-state gives the following value for fluid viscosity: $\mu=0.296 \mathrm{cp}$. Weatherly Laboratories, by comparison, reports a value of $\mu=$ $0.395 \mathrm{cp}$. 
-

• 


\section{APPENDIX B}

Pressure drawdown solutions for a well producing from (1) concentric regions of differing permeabilities, and (2) a region bounded by two intersecting faults

\section{B.1 WELL PRODUCING FROM CONCENTRIC REGIONS OF DIFFERENT PERMEABILITIES}

We consider a fully penetrating well located at the axis of a radial system of two concentric regions of differing permeabilities $k_{1}$ (region 1 ) and $k_{2}$ (region 2).

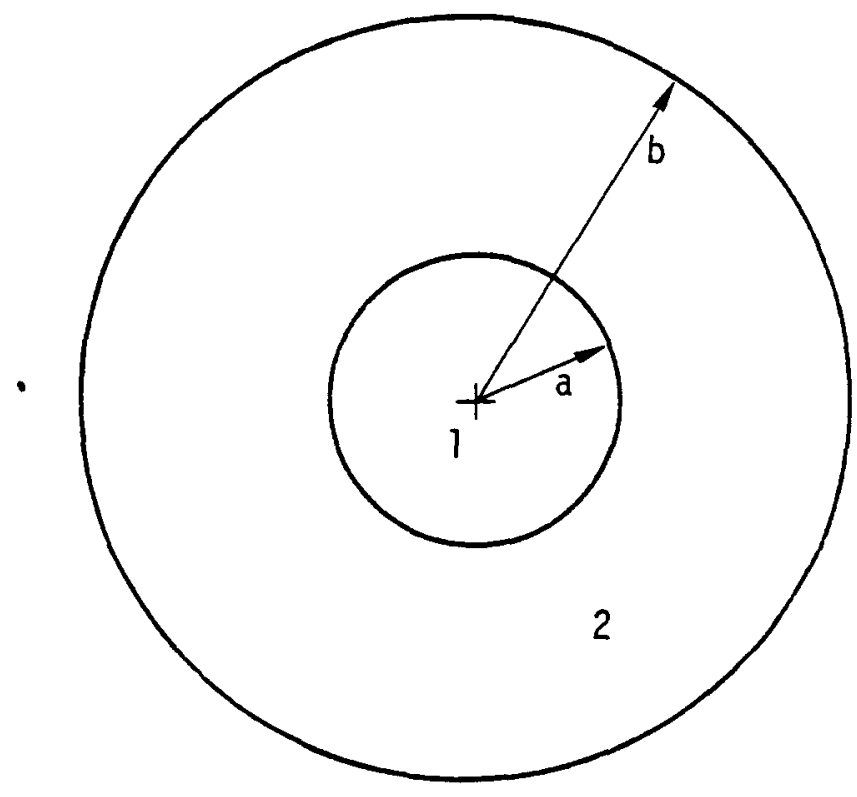

Figure B-1. Problem configuration. The well $(x)$ is located at the geometric center of region 1 . The outer boundary $r=b$ is assumed to extend to infinity. 
Other properties (porosity $\phi$, fluid viscosity $\mu$, formation volume factor $B$ and compressibility $C_{T}$ ) are assumed to be identical for the two regions. The reservoir configuration is shown in Figure B-1. This case ("sands in series") has been considered by Hurst [1960]. For constant rate of volume production $q(S T B / D)$, the pressure drop at the sandface is given by:

$$
\begin{aligned}
& \Delta p=\frac{141.2 q \mu B}{k_{1} h} p_{D}\left(t_{D}\right) \\
& p_{D}\left(t_{D}\right)=\frac{4}{\pi^{2}} \int_{0}^{\infty} \frac{\left(1-e^{-v^{2} t_{D}}\right) J_{0}\left(v r_{D}\right) d v}{v^{3}\left[M^{2}(n v)+N^{2}(n v)\right]} \\
& t_{D}=\frac{0.000264 k_{1} t}{\phi \mu C_{T} a^{2}} \\
& r_{D}=r_{w} / a \\
& n=\left(k_{1} / k_{2}\right) 0.5 \\
& M(\pi v)=J_{0}(v) J_{1}(n v)-n J_{1}(v) J_{0}(n v) \\
& N(n v)=J_{0}(v) Y_{1}(n v)-n J_{1}(v) Y_{0}(n v)
\end{aligned}
$$

where $J_{0}, J_{1}, Y_{0}$ and $Y_{1}$ denote the Bessel functions. The integral in Equation (B-2) is quite complicated and must be evaluated numerically.

In Section B.3, we will present numerical results for $\Delta p$ with the following values for the various parameters:

$$
\begin{aligned}
k_{1} & =180 \mathrm{md} \\
k_{1} / k_{2} & =12 \\
\emptyset & =0.2
\end{aligned}
$$




$$
\begin{aligned}
B & =1.05 \mathrm{RB} / \mathrm{STB} \\
\mathrm{h} & =27 \mathrm{ft} \\
r_{W} & =0.25 \\
\mathrm{a} & =200 \mathrm{ft} \\
\mathrm{q} & =15,000 \mathrm{STB} / 0 \\
C_{T} & =6.5 \times 10^{-6} \mathrm{psi}^{-1}
\end{aligned}
$$

B.2 WELL PRODUCING FROM A REGION BOUNDED BY TWO INTERSECTING FAULTS

We consider a fully penetrating well located at a distance $d / 2$ from two intersecting faults (graben angle $=\alpha$ ). The reservoir configuration is shown in Figure B-2. The solution for this case can be obtained by superposition.

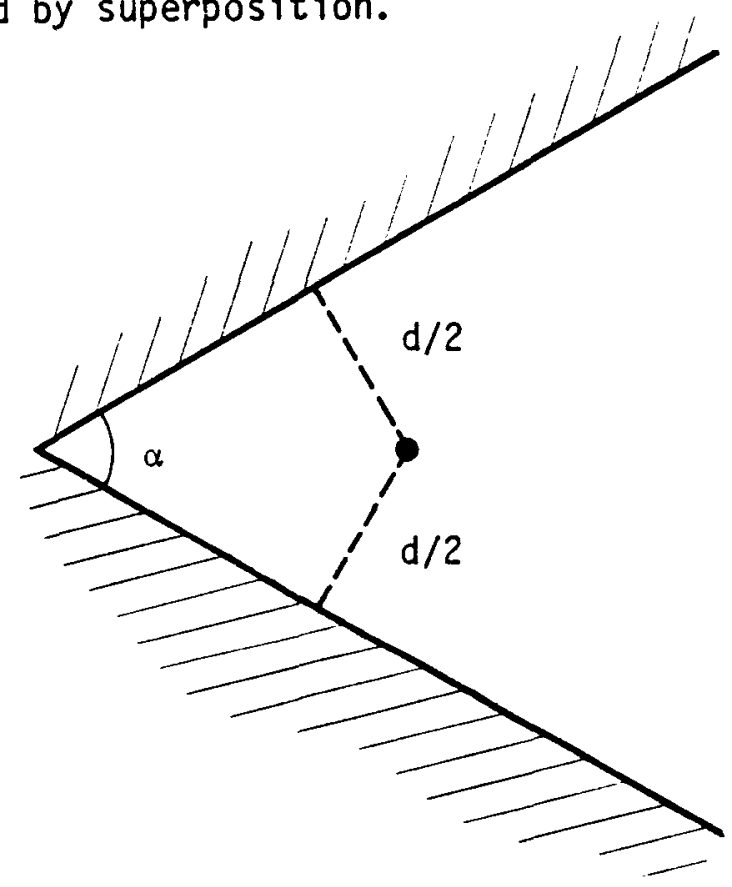

Figure B-2. Reservoir configuration employed. The well (•) is located at a distance (d/2) from two intersecting faults with a graben angle $\alpha$.

For $\alpha=30^{\circ}$ (The well drains $1 / 12$ of the circular region. The graben angle $\alpha$ is chosen such that $\alpha=360 k_{2} / k_{1}$. ) the system of image wells required to construct the solution is shown in Figure $B-3$. The pressure drop $\Delta p$ in this case is given by: 


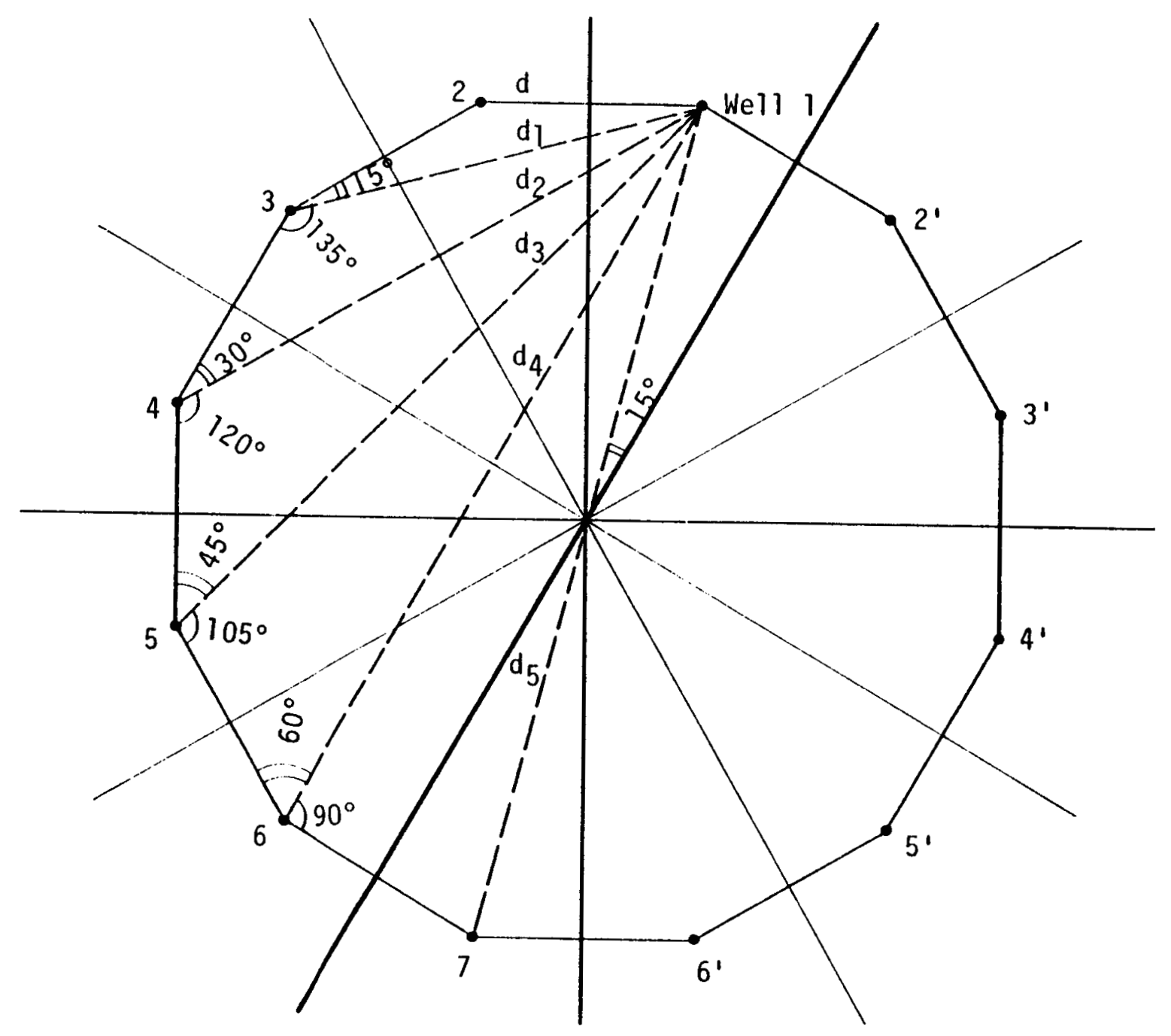

Figure B-3. System of Image Wells $\left(2,2^{\prime}, 3,3^{\prime}, 4,4^{\prime}, 5,5^{\prime}, 6,6^{\prime}, 7\right)$ required to construct solution for a single well (Well 1) producing from a region bounded by two faults with a graben angle of $30^{\circ}$. 


$$
\Delta p=\frac{141.2 q_{\mu} B}{k h} p_{D}^{\prime}(t)
$$

where

$$
\begin{aligned}
& P_{D}^{\prime}(t)=-\frac{1}{2}\left[E i\left(-y r_{w}^{2}\right)+2 E i\left(-y d^{2}\right)\right. \\
& +2 E i\left(-y d_{1}^{2}\right)+2 E i\left(-y d_{2}^{2}\right) \\
& \left.+2 E i\left(-y d_{3}^{2}\right)+2 E i\left(-y d_{4}^{2}\right)+E i\left(-y d_{5}^{2}\right)\right] \\
& y=\emptyset \mu C_{T} /(0.001056 k t) \\
& d_{1}=d \sin 150^{\circ} / \sin 15^{\circ} \\
& d_{2}=d \sin 135^{\circ} / \sin 15^{\circ} \\
& d_{3}=d \sin 120^{\circ} / \sin 15^{\circ} \\
& d_{4}=d \sin 105^{\circ} / \sin 15^{\circ} \\
& d_{5}=d / \sin 15^{\circ}
\end{aligned}
$$

In Section $B-3$, we will present numerical results for $\Delta p$ (Equation $(B-8)$ ) with the following values for $k$ and $d: k=180 \mathrm{md}, d=500$ ft. All other reservoir parameters for this case are identical with those given in Section B-1. 


\section{B-3 COMPARISON OF SOLUTIONS}

The pressure drawdown solutions given by Equations (B-1) and $(B-8)$ are plotted and compared in Figures $B-4$ and $B-5$. At early times (Figure $B-4$ ), the two solutions are identical; this is to be expected in view of the fact that it will be sometime before the effects of radial discontinuities and/or bounding faults are felt at the sandface. With the passage of time, the two solutions do diverge. The sands in series solution (Equation (B-1)) predict a somewhat higher pressure drop. At late times, the two solutions give two straight lines with identical slopes (Figure $B-5$ ); the two straight lines are, however, separated by approximately one-fifth of a log cycle. From a practical standpoint, in the absence of some geological indication, it would be thus, very difficult to choose between the two solutions on the basis of test data from a single wel1 (such as MG-T/DOE AMOCO FEE No. 1 Wel1). 


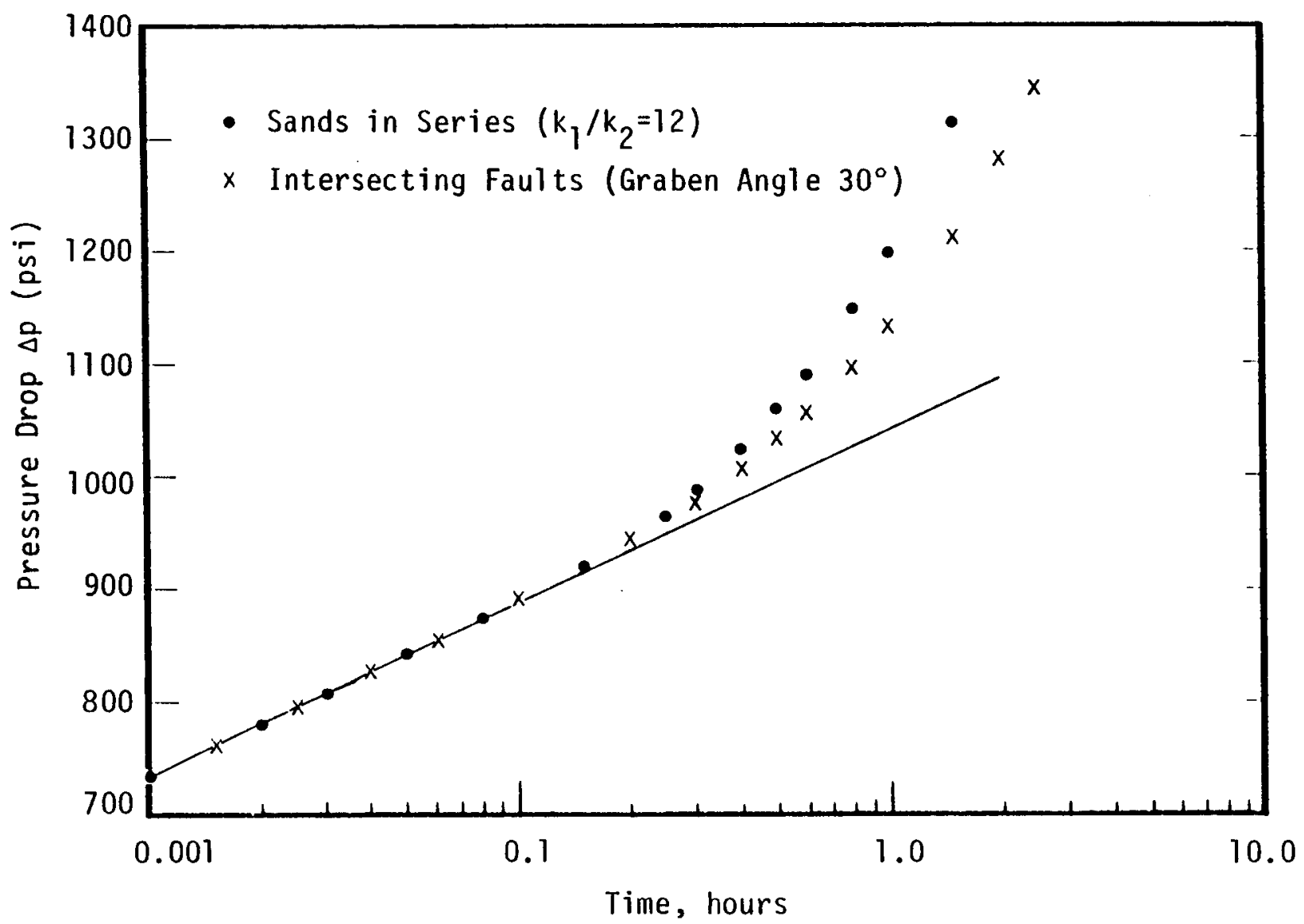

Figure B-4. Early Time Pressure Drop 


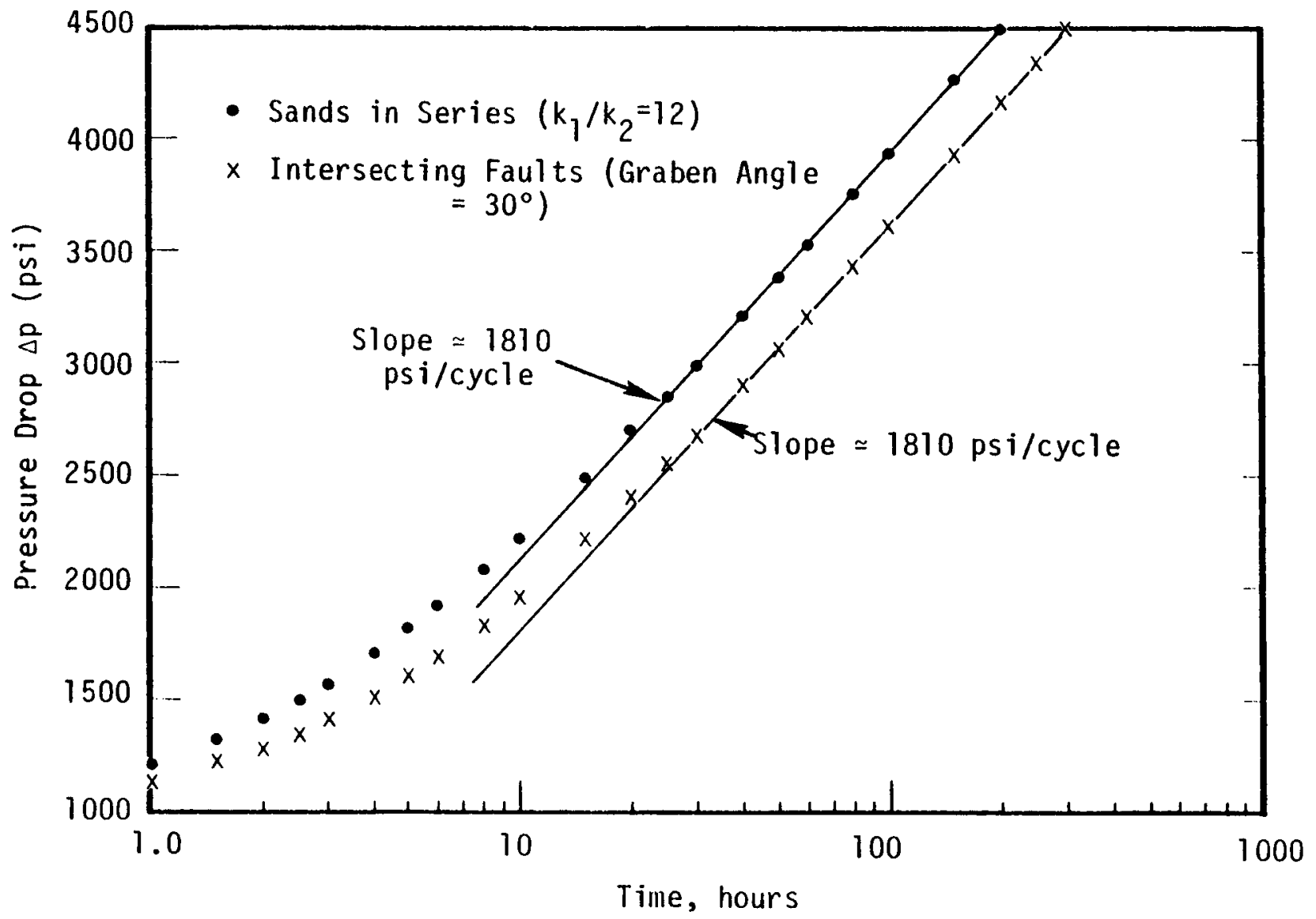

Figure B-5. Late-Time Pressure Drop 